\title{
The Addition of Midazolam Reduces the Incidence of Early Postoperative Nausea and Vomiting in Short Time Gynecological Procedures
}

\author{
Vsevolod Rozentsveig*, Evgeni Brotfain*, Moti Klein, Leonid Koyfman, Mathew Boyko, \\ Alexander Zlotnik \\ Division of Anesthesiology and Critical Care, Soroka University Medical Center and Faculty of Health Sciences, \\ Ben-Gurion University of the Negev, Beer-Sheva, Israel \\ Email: amaliaro@012.net.il
}

Received 16 November 2014; accepted 15 January 2015; published 20 January 2015

Copyright (C) 2015 by authors and Scientific Research Publishing Inc.

This work is licensed under the Creative Commons Attribution International License (CC BY). http://creativecommons.org/licenses/by/4.0/

\section{cC) (i) Open Access}

\begin{abstract}
Background: If untreated, one third of patients who undergo surgery develop postoperative nausea and/or vomiting (PONV). The prevention of postoperative nausea and vomiting can improve satisfaction among vulnerable patients. We hypothesized that preoperative anxiety may increase the incidence of PONV. The objective was to assess whether administration of a benzodiazepine prior to surgery would reduce the incidence of PONV. Methods: 130 women (ASA I and II) scheduled to undergo dilatation and curettage comprised the study group. The women were allocated randomly to two study groups according to the type of anesthesia administered (with and without midazolam). Results: Sixty-eight women received midazolam and 62 did not. Patients treated with midazolam were feeling more comfortable ("friendliness", $p=0.005$ and "elation", $p=0.01$ ) and had less postoperative fatigue $(p=0.04)$ than non-midazolam-treated group. Patients treated with midazolam had significantly fewer emetic episodes during the first 4 hours after surgery than those without midazolam $(0.1 \pm 0.2$ vs $0.3 \pm 0.6$, respectively, $p=0.003)$. Conclusions: Midazolam reduces the incidence of PONV and improves patient's comfort. We suggest that midazolam has to be routinely included in the anesthesia protocol for short-term gynecological procedures (dilatation and curettage).
\end{abstract}

\section{Keywords}

Anxiety, Midazolam, Postoperative Nausea and Vomiting

\footnotetext{
*Drs. Rozentsveig and Brotfain contributed equally to the paper.
} 


\section{Introduction}

Postoperative nausea and vomiting (PONV) are commonly seen after surgical procedures that require general anesthesia. PONV may prolong postoperative morbidity and delay discharge from the hospital [1]. Since anesthesia is administered to more than 75 million surgical patients annually worldwide [2] and since the incidence of vomiting during the first postoperative day is as high as $25 \%-40 \%$ [3], the enormous economic cost of this complication in terms of medical expenditure is obvious. In the United States alone, the calculated annual cost of PONV reaches several hundred million dollars [4].

It is normally assumed that PONV has a multifactorial origin with patient-related factors (female gender, history of motor sickness, smoking, and previous PONV), anesthesia-related factors (mask ventilation, volatile anesthetics, and opioids) and surgery-related factors (site and duration of surgery, and laparoscopic techniques) [5]. Laparoscopic techniques and long time procedures are traditionally associated with high incidence of PONV [5]. Surprisingly, there is a few clinical data about PONV after short time, day case surgical procedures [6].

Because preoperative anxiety was recognized as an additional risk factor for emesis by some authors [7], we conducted a prospective controlled randomized study designed to assess the possibility that the addition of midazolam to anesthesia induction could reduce the incidence of PONV after short time gynicological procedures.

\section{Materials and Methods}

The Human Research and Ethics Committee at Soroka Medical Center in Beer-Sheva, Israel approved this study (RN 3530). This is a single-center, prospective and randomized study.

Adult 130 women patients of American Society of Anesthesiologists physical classification status (ASA) I and II were included to our study after dilatation and curettage procedures. All patients signed written informed consent before the beginning of procedure.

The patients' pre-operative anxiety state was assessed by the Profile of Mood Stated (POMS) [8], which was completed for each patient 30 minutes before they entered the operating room by an anesthesia resident who had been previously trained in the appropriate interview technique.

The POMS assesses anxiety, depression, anger, vigor, fatigue, confusion, friendliness and elation on a fivepoint scale ranging from zero ("not at all”) to 4 ("maximal”).

Immediately after the interview was completed a 22-gauge intravenous catheter was inserted into a peripheral vein and the patients picked a closed envelope according to which they were randomized to receive either midazolam $0.01 \mathrm{mg} / \mathrm{kg}$ IV or saline in the same volume.

All patients were divided into two study groups according to anesthetic setup. Patients in Group 1 received intravenously midazolam $0.01 \mathrm{ml} / \mathrm{kg}$ in addition to propofol $(2 \mathrm{mg} / \mathrm{kg})+$ fentanyl $(1 \mathrm{mcq} / \mathrm{kg})$ anesthetic setup. Group 2 patients were anesthetized intravenously with propofol $(2 \mathrm{mg} / \mathrm{kg})+$ fentanyl $(1 \mathrm{mcq} / \mathrm{kg})$ setup and received subsequent volume of normal saline.

In each group age, weight, height, duration of operation, and BMI were recorded. Any history of previous PONV or motion sickness was also noted.

A second anesthesiologist who was blinded to the anxiolytic administered conducted anesthesia. A second closed envelope was chosen to determine the study group affiliation.

A $50 \mathrm{mg}$ diclofenac suppository was given for postoperative analgesia immediately at the end of the procedure and the patients were transferred to the recovery room. After full emergence from anesthesia (assessed by self correction of a wrong ID number) the patients were asked to grade the intensity of nausea, vomiting and retching on a five-point scale from zero ("not at all”) to 4 ("maximal”). This item was repeated a half-hour later and before discharge home from the outpatient department (approximately $4 \mathrm{~h}$ after the operation).

A phone call interview was performed by a third physician blinded to the results of the two previous study phases, 24 and 48 hours after discharge. At this time the interviewer assessed nausea, vomiting, limitation of ordinary activities and need for medication, using a previously described questionnaire [9].

\section{Statistical Analysis}

Bivariate hypotheses involving continuous variables were tested with a $t$ test or ANOVA for independent groups with normal distribution and Mann-Whitney or Kruskal-Wallis tests for non-normal distribution. Normality of the study data was tested with a 1-sample Kolmogorov-Smirnov test to indicate the appropriateness of parametric testing. To determine if the distribution of categorical variables differed across study groups, the $\chi^{2}$ test was 
used. The Fisher exact test was applied when appropriate. Continuous variables were expressed as mean \pm SD, and categorical variables were expressed as percentages. Logistic regression analysis was used for multivariate comparisons of factors associated with nausea (VAS score above 0 ; 48 hours after the procedure). All variables found in the univariate analyses to be associated with higher VAS scores at 48 hours ( $\mathrm{p}$ value $<0.1$ ) were entered into the model. All reported $\mathrm{p}$ values are two-sided and $\mathrm{p}<0.05$ was considered significant. Statistical analyses were performed with SPSS software (version 12.0.1, SPSS Inc.).

\section{Results}

One hundred and thirty women were offered to participate in the prospective, randomized study over a one-year period. Finally, 130 participants were included in the present study. Sixty-eight (68) patients were randomized in study Group 1 (midazolam treated-midazolam $0.01 \mathrm{ml} / \mathrm{kg}+$ propofol/fentanyl). Sixty-two (62) patients were randomly included in no-midazolam-treated study Group 2 (normal saline $0.01 \mathrm{ml} / \mathrm{kg}+$ propofol/fentanyl).

There was no statistically significant difference in age, weight, height and BMI between both study groups ( $p>0.05$, Table 1). There were no differences among the groups in incidence of previous PONV in past medical history ( $p>0.05$, Table 1 ). The duration of anesthesia was significantly less in midazolam treated group patients vs non-midazolam treated group (12.5 \pm 4.3 vs $13.0 \pm 3.8$ minutes, $\mathrm{p}=0.01$, Table 1$)$. Despite reaching of statistical significance, this difference has no clinical significance.

Patients treated with midazolam (Group 1) were feeling more comfortable (more friendly and elated) than non-midazolam treated group ( $\mathrm{p}=0.005$ and 0.01 , respectively). Moreover, Group 1 patients had less fatigue score than Group 2 ( $\mathrm{p}=0.04$, Table 2). Surprisingly, there were no differences in anxiety, depression or anger feeling in postoperative period between both study groups ( $p>0.05$, Table 2$)$.

Patients who treated with midazolam (Group 1 ) had significantly fewer incidences of emetic episodes during four hours after procedure $(p=0.003$, Table 3 ). Immediate (up to $30 \mathrm{~min}$ after procedure) postoperative events of nausea, vomiting and retching were similar between both study groups ( $p>0.05$, Table 3 ). There is no difference in VAS score between both study groups ( $p>0.05$, Table 3).

A phone call interview was provided 24 and 48 hours as a part of clinical follow up of all study group patients (see "Methods"). During forty-eight hours after procedure seventeen patients (13.1\%) complained of limitation in at least one daily activity and $13(10.0 \%)$ reported that they were limited in the preparation or consumption of food in Group 1 and nineteen patients had limitation in at least one daily activity (25.0\%), and twelve patients had some type of meal intolerance $(17.9 \%)$ in Group $2(\mathrm{p}<0.05)$.

\section{Discussion}

PONV is common following surgery and can affect more than $25 \%-40 \%$ of anesthetized patients [10] [11]. PONV was cited by $71 \%$ of patients as their worst postoperative symptom and it was the major reason for poor ratings in the post-surgery period. Many patients would have been willing to accept more pain if it resulted in a reduction in nausea and vomiting [7]. Reducing the incidence of these distressing complications can improve satisfaction with anesthesia in the high risk PONV group [12].

Table 1. Demographic data, past medical history of PONV and duration of anesthesia in both study groups. Group 1, midazolam treated; Group 2, non-midazolam treated. There was no statistically significant difference between groups in terms of age, weight, BMU and history of PONV. The duration of anesthesia, despite reaching of statistical significance, has no clinical significance. The data is presented as mean $\pm \mathrm{SD}$.

\begin{tabular}{|c|c|c|c|}
\hline & Group $1(n=68)$ & Group $2(n=62)$ & $\mathrm{p}$ \\
\hline Age (years) & $34.4 \pm 13.2$ & $38.3 \pm 12.4$ & 0.58 \\
\hline Weight (kg) & $71.1 \pm 16.2$ & $69.3 \pm 18.4$ & 0.55 \\
\hline Height (cm) & $162.0 \pm 12.8$ & $162.0 \pm 12.8$ & 0.97 \\
\hline Body mass index (weight/height ${ }^{2}$ ) & $27.1 \pm 6.3$ & $25.4 \pm 4.7$ & 0.09 \\
\hline Duration of anesthesia (min) & $12.5 \pm 4.3$ & $13.0 \pm 3.8$ & 0.01 \\
\hline History of PONV (\%) & $13(19.1)$ & $11(17.7)$ & 0.84 \\
\hline
\end{tabular}


Table 2. Clinical data of postoperative patients comfort and mood. POMS scale from 0 to 4, where zero means "not at all" and 4 means "maximally graded"*. Group 1, midazolam treated; Group 2 non-midazolam treated. There were no statistically significant differences in terms of anxiety, depression, anger, vigor and confusion, but score of fatigue, friendliness and elation was better in midazolam treated group. Data is presented as median \pm range.

\begin{tabular}{|c|c|c|c|c|}
\hline & All patients $(n=130)$ & Group $1(n=68)$ & Group $2(n=62)$ & $\mathrm{p}$ \\
\hline Anxiety & $1.3 \pm 1.4$ & $1.5 \pm 1.5$ & $1.1 \pm 1.4$ & 0.18 \\
\hline Depression & $0.4 \pm 0.8$ & $0.4 \pm 0.8$ & $0.5 \pm 1.0$ & 0.98 \\
\hline Anger & $0.6 \pm 1.0$ & $0.6 \pm 1.0$ & $0.5 \pm 1.0$ & 0.33 \\
\hline Vigor & $0.5 \pm 1.0$ & $0.5 \pm 1.0$ & $0.6 \pm 1.0$ & 0.37 \\
\hline Fatigue & $1.1 \pm 1.3$ & $0.9 \pm 1.2$ & $1.3 \pm 1.2$ & $0.04^{* *}$ \\
\hline Confusion state & $0.8 \pm 1.3$ & $0.7 \pm 1.2$ & $0.9 \pm 1.3$ & 0.26 \\
\hline Friendliness & $1.3 \pm 1.7$ & $1.7 \pm 1.8$ & $1.0 \pm 1.5$ & $0.005^{* * *}$ \\
\hline Elation & $0.6 \pm 1.0$ & $0.8 \pm 1.2$ & $0.3 \pm 0.7$ & $0.01^{* *}$ \\
\hline
\end{tabular}

${ }^{*}$ Non-parametric distribution values were compared with the Mann-Whitney test. ${ }^{* *}$ p value $<0.05$ was defined as statistically significant. ${ }^{* * *}$ p value $<$ 0.01 was defined as extremely statistically significant.

Table 3. Clinical data of emetic episodes, nausea, retching and VAS score both study groups*. Group 1, midazolam treated; Group 2, non-midazolam treated. There were no statistically significant differences in terms of VAS and incidence of nausea and vomiting in $30 \mathrm{~min}$ after the surgery. The incidence of emetic episodes during 1 st 4 hours was lover in midazolam treated group. Data is presented as median \pm range.

\begin{tabular}{cccc}
\hline & Group 1 ( $\mathrm{n}=68)$ & Group 2 (n=62) & $\mathrm{p}$ \\
\hline Nausea $>$ 3 (30 min) & $0.3 \pm 0.9$ & $0.3 \pm 0.5$ & 0.23 \\
Vomiting > 3 (30 min) & $0.1 \pm 0.5$ & $0.1 \pm 0.2$ & 0.37 \\
Retching > 3 (30 min) & $0.1 \pm 0.3$ & $0.1 \pm 0.2$ & 0.60 \\
Emetic episodes during 1st 4 hours after operation (>3 in one hour) & $0.1 \pm 0.2$ & $0.3 \pm 0.6$ & $0.003^{* *}$ \\
VAS: mean nausea score during hospital state & $0.6 \pm 1.7$ & $0.8 \pm 1.4$ & 0.11 \\
\hline
\end{tabular}

*Non-parametric values were compared with the Mann-Whitney test. ${ }^{* *}$ p value $<0.05$ was defined as statistically significant.

Several factors may be associated with and influence PONV, including gender, weight (BMI), age, history of motion sickness or previous PONV, and type and duration of surgery and anesthesia [13]-[16]. The incidence of emetic episodes in gynecological patients during the initial 24-hour post-operative period is higher than 50\% [3]. Most of published data showed high incidence of PONV after laparoscopic and long-term gynecological procedures [17] [18].

Studies have reported that PONV is also associated with day case surgical procedures, with an incidence of 8\% - 45\% [19]-[22]. Day-case surgery represents a large and increasing fraction of all surgical procedures throughout the world. Data from the USA, Canada and UK show that by the mid-1990s, 50\% - 60\% of all elective procedures were day-case surgery [23] and the NHS Plan predicts that $75 \%$ of all elective operations will be carried out as day cases [24]. PONV is the most common reason for unplanned hospital admission following day-case surgery with a significant impact on patient satisfaction, discharge times and cost [25].

To fully examine the impact of any illness, both the direct and indirect associated costs should be considered. Direct costs are those resources (medical and non-medical) expended to prevent and treat illness. Indirect costs are expenditures secondary to the illness, e.g., loss of productivity [22]. In addition to the cost incurred by PONV as a result of unplanned hospital admissions, patients undergoing ambulatory surgery may suffer a reduction in personal income [1] due to persistent PONV after discharge from the hospital. Furthermore, other family members or friends may miss work and lose income due to the need to care for the patient at home.

The association between anxiety and increased nausea and vomiting during pregnancy is well established [26]. However, its role in PONV is less clear. Some authors [7] have reported a strong correlation between preopera- 
tive anxiety and PONV, while others have reported only a weak association or no association at all [27].

Midazolam was previously reported to be effective in the treatment of persistent PONV [28] and more recently Bauer and collaborators [29] reported that patients receiving midazolam as premedication had a significant lower incidence of PONV than placebo group patients.

Moreover, an addition of midazolam to ramosetron has been shown to reduce the incidence of PONV in laparoscopic gynecological procedures [10].

Our patients also showed a significant reduction in PONV among those who received midazolam. This difference was more accentuated 4 hours after procedures and 48 hours after discharge.

The postulated mechanisms of action of benzodiazepines in the reduction of PONV may include glycinemimetic inhibitory effects in the spinal cord and brainstem, enhancing the inhibitory effects of gamma amino butyric acid in the brain, and also may involve decreased adenosine reuptake increasing adenosine-mediated inhibition of dopamine synthesis, release and action in the chemoreceptor trigger zone [28].

An interesting observation of our study is that patients experienced PONV at home 48 hours after discharge, even though many of them did not experience it during their hospital state. There is no previously published clinical data about during clinical follow up of PONV two days after short-term day case procedures. Chung and co-workers [30] reported that PONV persisted for 24 hours after ambulatory anesthesia. However, they limited their postoperative follow-up to 24 hours only. Had their follow-up period been longer they might have found a similar result.

As expected, during the 48 hours after discharge, patients experiencing PONV were significantly more likely to report impairment in the performance of normal daily activities than those who did not experience nausea and vomiting. It might be increase the indirect costs of the procedure due to delayed return to work or loss of production due to the need for a caregiver during this period.

It is important to be aware of the total costs of an illness and the elements that contribute to this total cost in order to reach informed decisions about alternative interventions for its control.

The results of the present study suggest a correlation between the level of anxiety and the occurrence of preand post-discharge nausea and vomiting. The impact of PONV is not limited to its economic consequences, as it has been demonstrated that nausea and vomiting have a perceived debilitating effect on the patient beyond that caused by the surgery itself.

Our study has a number of limitations. It is a single-center prospective study with a small number of participants. Our study has no data about an economical analysis of the total costs of illness and post procedural hospitalization. Future investigations in multicenter, randomized trials might include the detailed analysis of clinical benefit and cost-effectiveness of benzodiazepine treatment in reduction of PONV after short-term, day case surgical procedures.

\section{Conclusion}

We consider that pre-operative anxiety should be taken into consideration in the multifactorial etiology of postoperative nausea and vomiting in addition to factors commonly associated with PONV such as BMI, duration of anesthesia, history of motion sickness and history of PONV even in short-term, day case surgical procedures. We suggest that midazolam should be routinely included in the anesthetic protocol for short-term gynecological procedures.

\section{Conflict of Interest Statement}

Drs. Vsevolod Rozentsveig, Evgeni Brotfain, Moti Klein, Leonid Koyfman, Mathew Boyko and Alexander Zlotnik declare that they have no conflict of interest.

\section{Authors Contribution Statement}

Dr. Vsevolod Rozentsveig: study design, data collection, data analysis, data interpretation, writing. Dr. Evgeni Brotfain: literature search, study design, data collection, data analysis, data interpretation, corresponding Author. Dr. Moti Klein: writing, critical revision. Dr. Mathew Boyko: data analysis, data interpretation. Dr. Leonid Koyfman: literature search, data analysis, data interpretation. Prof. Alexander Zlotnik: writing, critical revision. 


\section{References}

[1] Hill, R.P., Lubarsky, D.A., Phillips-Bute, B., Fortney, J.T., Creed, M.R., Glass, P.S., et al. (2000) Cost-Effectiveness of Prophylactic Antiemetic Therapy with Ondansetron, Droperidol, or Placebo. Anesthesiology, 92, 958-967. http://dx.doi.org/10.1097/00000542-200004000-00012

[2] Apfel, C.C., Korttila, K., Abdalla, M., Kerger, H., Turan, A., Vedder, I., et al. (2004) A Factorial Trial of Six Interventions for the Prevention of Postoperative Nausea and Vomiting. New England Journal of Medicine, 350, 2441-2451. http://dx.doi.org/10.1056/NEJMoa032196

[3] Koivuranta, M., Laara, E., Snare, L. and Alahuhta, S. (1997) A Survey of Postoperative Nausea and Vomiting. Anaesthesia, 52, 443-449. http://dx.doi.org/10.1111/j.1365-2044.1997.117-az0113.x

[4] Watcha, M.F. (2000) The Cost-Effective Management of Postoperative Nausea and Vomiting. Anesthesiology, 92, 931-933. http://dx.doi.org/10.1097/00000542-200004000-00007

[5] Stadler, M., Bardiau, F., Seidel, L., Albert, A. and Boogaerts, J.G. (2003) Difference in Risk Factors for Postoperative Nausea and Vomiting. Anesthesiology, 98, 46-52. http://dx.doi.org/10.1097/00000542-200301000-00011

[6] Gan, T.J., Meyer, T.A., Apfel, C.C., et al. (2007) Society for Ambulatory Anesthesia Guidelines for the Management of Postoperative Nausea and Vomiting. Anesthesia Analgesia, 105, 1615-1628. http://dx.doi.org/10.1213/01.ane.0000295230.55439.f4

[7] Watcha, M.F. and White, P.F. (1992) Postoperative Nausea and Vomiting. It's Etiology, Treatment and Prevention. Anesthesiology, 77, 162-184. http://dx.doi.org/10.1097/00000542-199207000-00023

[8] Lichtor, J.L., Johanson, C.E., Mhoon, D., Faure, E.A., Hassan, S.Z. and Roizen, M.F. (1987) Preoperative Anxiety: Does Anxiety Level the Afternoon before Surgery Predict Anxiety Level Just before Surgery? Anesthesiology, 67, 595599. http://dx.doi.org/10.1097/00000542-198710000-00031

[9] Carroll, N.V., Miederhoff, P., Cox, F.M. and Hirsch, J.D. (1995) Postoperative Nausea and Vomiting after Discharge from Outpatient Surgery Centers. Anesthesia Analgesia, 80, 903-909.

[10] Rabey, P.G. and Smith, G. (1992) Anaesthetic Factors Contributing to Postoperative Nausea and Vomiting. British Journal of Anaesthesia, 69, 40S-45S. http://dx.doi.org/10.1093/bja/69.supplement_1.40S

[11] Wetchler, B.V. (1991) Outpatient Anesthesia. What Are the Problems in the Recovery Room? Canadian Journal of Anesthesia, 38, 890-894. http://dx.doi.org/10.1007/BF03036968

[12] Eberhart, L.H., Hogel, J., Seeling, W., Staack, A.M., Geldner, G. and Georgieff, M. (2000) Evaluation of Three Risk Scores to Predict Postoperative Nausea and Vomiting. Acta Anaesthesiologica Scandinavica, 44, 480-488. http://dx.doi.org/10.1034/j.1399-6576.2000.440422.x

[13] Kenny, G.N. (1994) Risk Factors for Postoperative Nausea and Vomiting. Anaesthesia, 49, 6-10. http://dx.doi.org/10.1111/j.1365-2044.1994.tb03576.x

[14] Paxton, L.D., McKay, A.C. and Mirakhur, R.K. (1995) Prevention of Nausea and Vomiting after Day Case Gynaecological Laparoscopy. A Comparison of Ondansetron, Droperidol, Metoclopramide and Placebo. Anaesthesia, 50, 403406. http://dx.doi.org/10.1111/j.1365-2044.1995.tb05993.x

[15] Apfel, C.C., Greim, C.A., Haubitz, I., Grundt, D., Goepfert, C., Sefrin, P., et al. (1998) The Discriminating Power of a Risk Score for Postoperative Vomiting in Adults Undergoing Various Types of Surgery. Acta Anaesthesiologica Scandinavica, 42, 502-509. http://dx.doi.org/10.1111/j.1399-6576.1998.tb05158.x

[16] Toner, C.C., Broomhead, C.J., Littlejohn, I.H., Samra, G.S., Powney, J.G., Palazzo, M.G., et al. (1996) Prediction of Postoperative Nausea and Vomiting Using a Logistic Regression Model. British Journal of Anaesthesia, 76, 347-351. http://dx.doi.org/10.1093/bja/76.3.347

[17] Park, J.W., Jun, J.W., Lim, Y.H., Lee, S.S., Yoo, B.H., Kim, K.-M., Yon, J.H. and Hong, K.H. (2012) The Comparative Study to Evaluate the Effect of Palonosetron Monotherapy versus Palonosetron with Dexamethasone Combination Therapy for Prevention of Postoperative Nausea and Vomiting. Korean Journal of Anesthesiology, 63, 334-339.

[18] D’souza, N., Swami, M. and Bhagwat, S. (2011) Comparative Study of Dexamethasone and Ondansetron for Prophylaxis of Postoperative Nausea and Vomiting in Laparoscopic Gynecologic Surgery. International Journal of Gynecology and Obstetrics, 113, 124-127. http://dx.doi.org/10.1016/j.ijgo.2010.11.022

[19] Korttila, K., Ostman, P., Faure, E., Apfelbaum, J.L., Prunskis, J., Ekdawi, M., et al. (1990) Randomized Comparison of Recovery after Propofol-Nitrous Oxide versus Thiopentone-Isoflurane-Nitrous Oxide Anaesthesia in Patients Undergoing Ambulatory Surgery. Acta Anaesthesiologica Scandinavica, 34, 400-403. http://dx.doi.org/10.1111/j.1399-6576.1990.tb03111.x

[20] Boysen, K., Sanchez, R., Krintel, J.J., Hansen, M., Haar, P.M. and Dyrberg, V. (1989) Induction and Recovery Characteristics of Propofol, Thiopental and Etomidate. Acta Anaesthesiologica Scandinavica, 33, 689-692.

http://dx.doi.org/10.1111/j.1399-6576.1989.tb02993.x 
[21] Edelist, G. (1987) A Comparison of Propofol and Thiopentone as Induction Agents in Outpatient Surgery. Canadian Journal of Anesthesia, 34, 110-116. http://dx.doi.org/10.1007/BF03015326

[22] Doze, V.A., Shafer, A. and White, P.F. (1988) Propofol-Nitrous Oxide versus Thiopental-Isoflurane-Nitrous Oxide for General Anesthesia. Anesthesiology, 69, 63-71. http://dx.doi.org/10.1097/00000542-198807000-00010

[23] Marcovic, M., Bandyopadhyay, M., Manderson, L., Allotey, P., Murray, S. and Vu, T. (2004) Day Surgery in Australia. Quantitative Research Report. Journal of Sociology, 40, 74-84. http://dx.doi.org/10.1177/1440783304040454

[24] Aylin, P., Williams, S., Jarman, B. and Bottle, A. (2005) Trends in Day Surgery Rates. British Medical Journal, 331, 803. http://dx.doi.org/10.1136/bmj.331.7520.803

[25] Green, G. and Jonsson, L. (1992) Nausea: The Most Important Factor Determining Length of Stay after Ambulatory Anaesthesia. Acta Anaesthesiologica Scandinavica, 36, 182-186.

[26] Andersson, L., Sundstrom-Poromaa, I., Wulff, M., Astrom, M. and Bixo, M. (2004) Implications of Antenatal Depression and Anxiety for Obstetric Outcome. Obstetrics Gynecology, 104, 467-476. http://dx.doi.org/10.1097/01.AOG.0000135277.04565.e9

[27] Wang, S.M. and Kain, Z.N. (2000) Preoperative Anxiety and Postoperative Nausea and Vomiting in Children: Is There an Association? Anesthesia Analgesia, 90, 571-575. http://dx.doi.org/10.1097/00000539-200003000-00014

[28] Di Florio, T. (1992) The Use of Midazolam for Persistent Postoperative Nausea and Vomiting. Anaesthesia and Intensive Care, 20, 383-386.

[29] Bauer, K.P., Dom, P.M., Ramirez, A.M. and O’Flaherty, J.E. (2004) Preoperative Intravenous Midazolam: Benefits beyond Anxiolysis. Journal of Clinical Anesthesia, 16, 177-183. http://dx.doi.org/10.1016/j.jclinane.2003.07.003

[30] Chung, F., Un, V. and Su, J. (1996) Postoperative Symptoms 24 Hours after Ambulatory Anaesthesia. Canadian Journal of Anesthesia, 43, 1121-1127. http://dx.doi.org/10.1007/BF03011838 
Scientific Research Publishing (SCIRP) is one of the largest Open Access journal publishers. It is currently publishing more than 200 open access, online, peer-reviewed journals covering a wide range of academic disciplines. SCIRP serves the worldwide academic communities and contributes to the progress and application of science with its publication.

Other selected journals from SCIRP are listed as below. Submit your manuscript to us via either submit@scirp.org or Online Submission Portal.
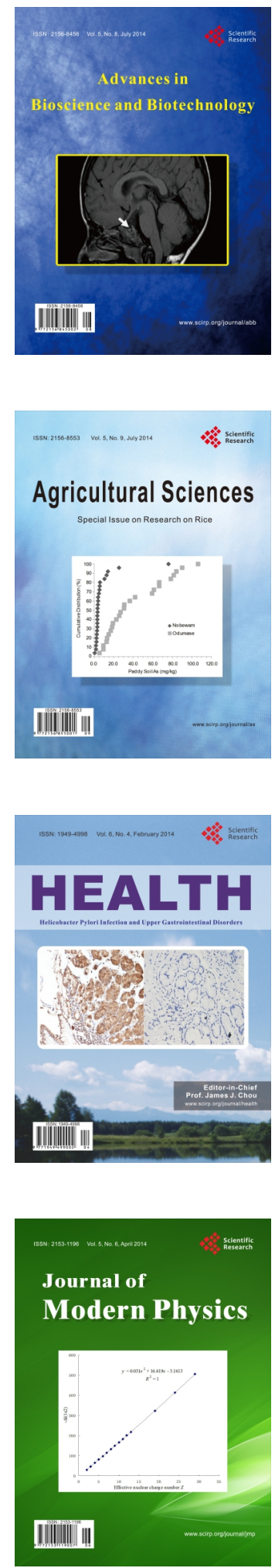
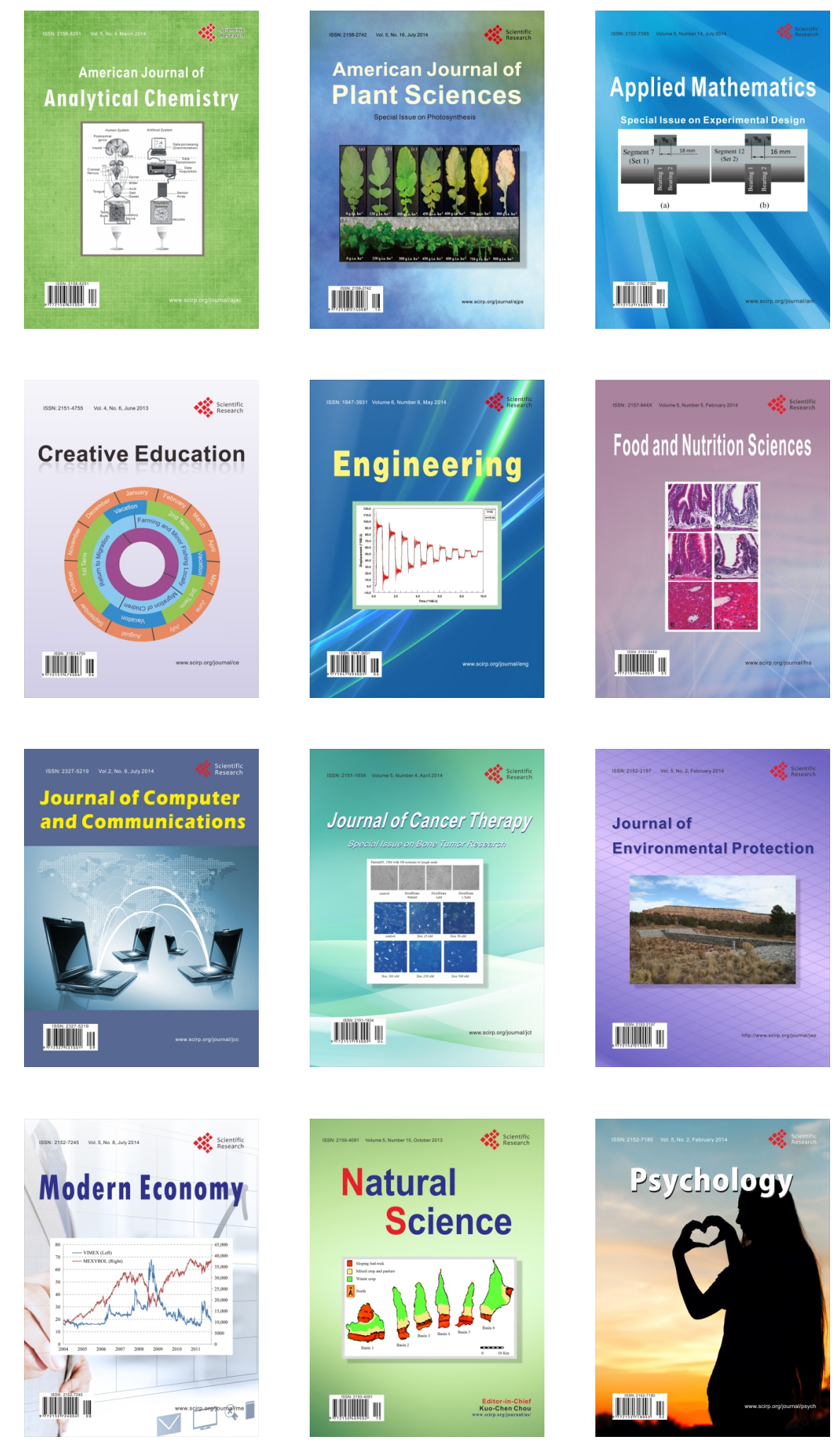